\title{
Familial psychiatric presentation of Huntington's disease
}

\author{
S Lovestone, S Hodgson, P Sham, A-M Differ, R Levy
}

Sections of Old Age Psychiatry and

Genetics,

Institute of Psychiatry,

De Crespigny Park,

Denmark Hill,

London SE5 8AF, UK

$S$ Lovestone

P Sham

$R$ Levy

Division of Medical

Genetics,

Guy's Hospital,

London, UK

$S$ Hodgson

A-M Differ

Correspondence to: Dr Lovestone.

Received 6 April 1995 Revised version accepted for Revised version accepted for
publication 16 October 1995

\begin{abstract}
Symptoms of schizophrenia may be encountered in Huntington's disease (HD) but usually when the full clinical syndrome is apparent; prechoreic psychosis is relatively uncommon. We describe a family where all four members affected with HD presented first with a severe psychiatric syndrome, which in three cases was schizophreniform in nature. Two other living members with no current signs of motor disorder have received psychiatric treatment, one for schizophrenia. Concurrence of psychosis and Huntington's disease in this family is unlikely to have occurred by chance, suggesting that there is some feature in this family which gives rise to the psychotic presentation. Families such as this may contribute to the investigation of genetic factors associated with psychiatric illnesses.

(f Med Genet 1996;33:128-131)
\end{abstract}

Key words: Huntington's disease; schizophrenia; psychosis.

Huntington's disease is an autosomal dominant neurodegenerative condition, the genetic basis of which is a CAG triplet repeat expansion at the $5^{\prime}$ end of a new gene on chromosome 4. ${ }^{1}$ The principal symptoms of Huntington's disease (HD), choreiform movements and dementia, are supplemented by a wide variety of psychiatric symptoms. Minor and major affective syndromes have been noted, as have behavioural and personality changes and schizophrenia-like symptoms. The reported

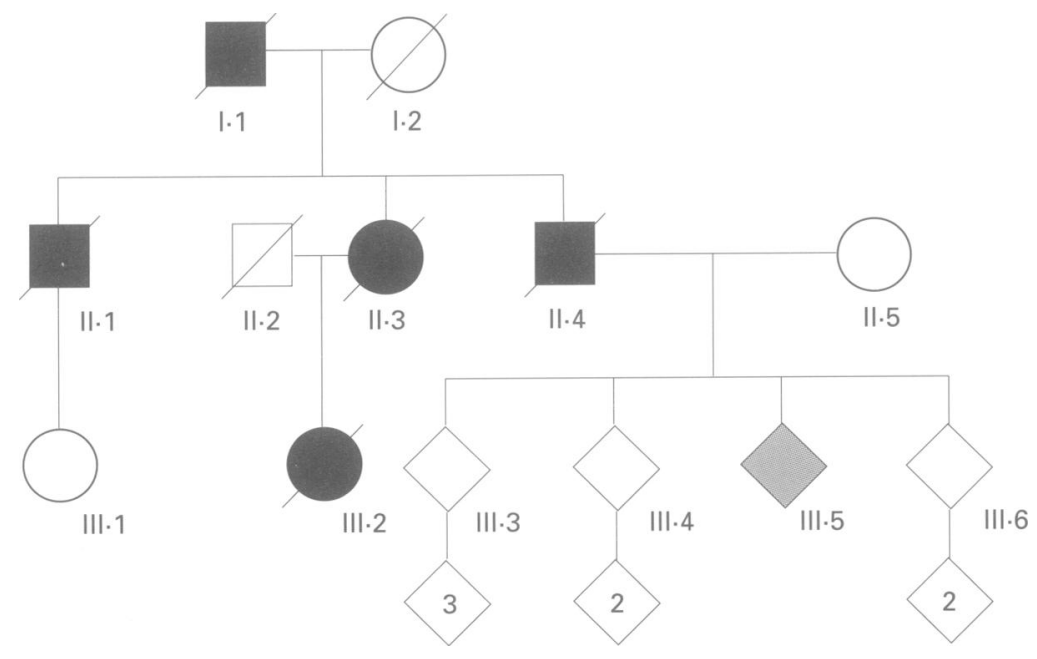

frequency and the timing of these symptoms relative to the movement disorder of dementia vary considerably, possibly because of ascertainment bias, but tend to occur after the onset of chorea. As a whole, functional psychiatric illness is reported in between $21 \%$ and $56 \%$ of patients with $\mathrm{HD}^{2}{ }^{2}$ For psychotic syndromes, rates reported vary from $5 \%$ to less than $17 \%$ of all patients with Huntington's disease. ${ }^{3-9}$ The cause of the psychotic symptoms that occur in some patients with $\mathrm{HD}$ is unknown. Is this a non-specific manifestation of the neurodegeneration or a specific syndrome in some subtypes of the disorder? We report here a family in which HD has been diagnosed, many members of which showed florid psychotic symptoms in the prechoreic stage of $\mathrm{HD}$.

\section{Patients and methods}

Subject II 4 was referred to the regional genetic clinic at Guy's Hospital, UMDS, because of a family history of $\mathrm{HD}$. Further information about other family members was obtained from interviewing informants and from the medical records where possible. The psychiatric symptoms and the case note diagnosis were recorded. DNA was obtained from blood stored from II 4 and tested for the expansion repeat in the HD gene using standard techniques. The family pedigree is shown in the figure.

\section{1}

At the age of 30 this man developed a tendency to become increasingly violent. His wife divorced him when he was 40 because of the persistent cruelty that he showed towards her. At the age of 54 he had clinically apparent chorea and died shortly thereafter.

II $\cdot 1$

At the age of 31 , over a period of about two weeks, this man became increasingly distrustful of his wife and thought she was trying to harm him. He believed that other people were trying to poison him and he dismantled the radio in order to find electronic "bugs". It appeared to his family that he was suffering from auditory hallucinations. He was admitted to a psychiatric hospital under a section of the Mental Health Act, then recovered, but was readmitted eight years later aged 39. At that time he was noted to be lethargic, to have poverty of thought, and psychomotor retardation; no chorea was present on neurological examination. $\mathrm{He}$ was treated with ECT and subsequently haloperidol and chlorpromazine. He then became euphoric 
and overexcited. Psychometric testing at that time showed a discrepancy between verbal and performance IQ indicating a possible organic component to his illness. He subsequently deteriorated with worsening dementia and frank chorea and died of pneumonia at the age of 50. The necropsy was reported as showing mild pathological atrophic changes but the full report is unavailable. The diagnosis was possible Huntington's disease.

II $\cdot 3$

At the age of 21 this woman was admitted to a psychiatric hospital where the diagnosis was made of depression; at that time a full neurological examination found no evidence of motor disorder but did note that she was fidgety and kept sniffing. Two years later she was admitted again with anxiety and depression and while on the ward made a suicide attempt. A neurologist found no evidence of motor disorder but did note again that she was fidgety. Two years later there was an appreciable tremor, unsteady gait, and dysarthria. A diagnosis of probable Huntington's disease was made. When she was 31 she became depressed again and by now a chorea was apparent. She was admitted and she remained in hospital thereafter, dying at the age of 38 .

II $\cdot 4$

This man first presented aged 40 with a florid psychosis. Three years later he was admitted on a section of the Mental Health Act; he had persecutory delusions believing that he was being followed by four Greeks and that neighbours were shining rays at his head, and, to prevent any damage, he always wore hats. He absconded, after which he assaulted a policeman and was admitted to prison. At the age of 44 he believed that he was being burned on his foot by welders who were inhabiting the room below his. It was noted for the first time that he had odd movements. One year later he was admitted again because of depression, ataxia, and dysarthria. He remained in hospital where he died aged 51. Subsequently it was shown using standard methods that he had one huntingtin gene allele with a repeat size of 18 and another with an expansion of 44 repeats.

III $\cdot 1$

This subject was said to have developed depression and aggressive outbursts starting in her mid 20s. She has received in patient psychiatric treatment for depression.

\section{III $\cdot 2$}

In her mid-twenties her family recognised that this woman was odd, displayed erratic behaviour, and had a violent temper. At the age of 28 she was admitted to a psychiatric hospital having been found in an excited state at a London railway station. A diagnosis of unspecified psychosis was made. At 30 she was again admitted to a psychiatric hospital; she was moody, impulsive, and talking in a fatuous manner. At the age of 32 fine choreiform movements were noted and Huntington's disease was diagnosed later that year. Four years later there were marked choreiform movements. She was by now violent and aggressive and needed continuing nursing care. She died at the age of 43. Necropsy examination of the brain showed moderate ventricular dilatation most marked in the anterior horns, small caudate and lentiform nucleus, and subthalamic nuclei atrophy; the diagnosis was of Huntington's disease.

\section{III $\cdot 5$}

At the age of 27 this patient was admitted to a psychiatric ward and a diagnosis made of a reactive depression following a break up with a partner. Three years later a psychotic illness developed with features of manic depression and paranoia; the patient believed that people were listening to telephone conservations, had decreased sleep, grandiosity, and periods of depression. On one occasion the patient was found wandering in the road having been to London to warn a sib about a threat of murder. Third person auditory hallucinations, people making derogatory comments, were noted. A diagnosis was made of schizoaffective disorder and treatment with neuroleptic medication started. Subsequently a number of relapses have occurred with withdrawal, depression, mild paranoia, and odd behaviour, but for much of the time the patient has remained asymptomatic while treated with depot preparations of neuroleptics. During one relapse, however, the symptomatology included third person auditory hallucinations of a derogatory nature, running commentary on thoughts, and delusions of persecution and self-reference. Examination has shown no signs of chorea or other motor disorder. Investigations included a SPET scan of the brain which showed bilateral frontal lobe hypoperfusion but normal caudate perfusion.

\section{Discussion}

Huntington's disease has been diagnosed in this family by clinical assessment in five subjects, confirmed by necropsy (in II·1 and III.2) and by molecular genetic studies (in II-4). Despite the problems of a retrospective case note study, considerable clinical information is available on four family members with diagnosed HD, and in all a major psychiatric disorder was a prominent part of the early symptomatology and appeared before motor disorder or dementia were noted. While detailed accounts of neurological assessment are not available for all family members it is clear that clinically apparent chorea was not present at the time of presentation. Furthermore, two family members with no current chorea or dementia have received psychiatric treatment, one for major depressive illness and another for a schizoaffective disorder. Neither of these subjects has opted to have the presymptomatic test for $\mathrm{HD}$ and so their risk status remains at $50 \%$. 
Psychiatric syndrome in relation to chorea

\begin{tabular}{|c|c|c|c|c|}
\hline Subject & $\begin{array}{l}\text { Age at initial } \\
\text { symptoms }\end{array}$ & Initial symptoms & $\begin{array}{l}\text { Age at onset } \\
\text { of chorea }\end{array}$ & $\begin{array}{l}\text { Age at } \\
\text { death }\end{array}$ \\
\hline $\begin{array}{l}\text { II } 1 \\
\text { II } \cdot 1 \\
\text { II } \cdot 3 \\
\text { II } \cdot 4 \\
\text { III } \cdot 1 \\
\text { III } \cdot 2 \\
\text { III } \cdot 5\end{array}$ & $\begin{array}{l}30 \\
31 \\
21 \\
40 \\
25 \\
28 \\
30\end{array}$ & $\begin{array}{l}\text { Behavioural disturbance } \\
\text { Schizophrenia/psychosis } \\
\text { Depression } \\
\text { Schizophrenia/psychosis } \\
\text { Depression } \\
\text { Schizophrenia/psychosis } \\
\text { Schizophrenia/psychosis }\end{array}$ & $\begin{array}{l}54 \\
40 \\
25 \\
44 \\
\text { None/current age } 39 \\
31 \\
\text { None/current age } 37\end{array}$ & $\begin{array}{r}>55 \\
50 \\
38 \\
51\end{array}$ \\
\hline
\end{tabular}

Relationships are often severely disrupted in families with $\mathrm{HD}$ and it might be hypothesised that this results in environmental stress sufficient to cause increased psychiatric illness in the offspring of those affected by HD. However, Jensen $e t a l,{ }^{10}$ in a case register study, showed that, while the rate of psychiatric illness in patients with $\mathrm{HD}$ was high, the rate in unaffected relatives was no higher than in controls, despite the shared environment. In a second study using direct psychiatric interview no cases of schizophrenia were found in over 50 unaffected at risk subjects. ${ }^{11}$

Psychiatric symptoms are common in $\mathrm{HD}$, but major functional psychiatric illness as reported here is considerably less so. In three out of four family members in this family, schizophrenia-like syndromes are apparent. This compares to overall figures in $\mathrm{HD}$ of less than $5 \%{ }^{1}$ to $12 \%{ }^{2}$ to $17 \%{ }^{4}$ Complex schizophrenia-like syndromes, as occur in this family, are uncommon in HD although isolated psychotic symptoms occur more frequently. One case note study found delusions of persecution in $23 \%$ of patients but these occurred often in the context of dementia. ${ }^{9}$

In the three cases of severe psychotic disorder in this family, schizophrenia preceded chorea by between three and nine years (table). Nonpsychotic psychiatric syndromes frequently occur before or at the time of the onset of chorea in HD. ${ }^{89}$ Prechoreic schizophrenia has been observed previously but the coincidence of prechoreic schizophrenia and prechoreic depression in all affected family members has not been previously reported. Interestingly, one study has suggested the possibility of familial aggregation of affective disorder in HD. Folstein and Folstein ${ }^{7}$ found, in a series of patients with $\mathrm{HD}$, an overall rate of depression of $32 \%$ which was prechoreic in a majority of cases. However, in detailed family studies it appeared that prechoreic depression was confined to certain families.

Why should HD present consistently as psychotic illness in the family reported here? One plausible explanation is that prechoreic presentation with schizophrenia in three out of four cases in a single family has occurred by chance. However, the similarity in presentation and the relatively late onset of choreiform movements or dementia is remarkable. Two alternative hypotheses are possible. Firstly, that HD is a heterogeneous condition and that the genetic subtype in this family causes both schizophrenia and HD phenotypes. However, in the one family member tested for the mutation, an expansion was found within the range reported for $\mathrm{HD}$ (more than 35 repeats). Thus it can be definitively shown that the condition itself is not heterogeneous at the level of the known mutations in the gene for the major syndrome. However, since the mutation is an expansion at the $5^{\prime}$ end of the gene, and may cause the disease by altering expression of the gene, it is possible that there is an as yet undetected difference in the gene itself which could alter the effects of the triplet repeat expansion. The second, alternative, explanation is that there is another entirely separate factor in this family that predisposes to either schizophrenia or depression. It can be postulated that this could lower the threshold for psychosis and that when combined with a compromised brain, as in family members with HD, results in a psychiatric phenotype. This could be multifactorial or the result of a gene in linkage disequilibrium with the HD gene or one which is common in the population. Clearly the status of two members of the family with psychiatric illness but no motor symptoms is important in further exploring the links between psychosis and HD in this family.

Several other neurodegenerative conditions may present with a schizophrenia-like syndrome. Dentatorubral-pallidoluysian atrophy (DRPLA) is an uncommon disorder presenting with choreoathetosis and dementia in addition to myoclonus and epilepsy, occurring more frequently in the Japanese population. Recently a triplet repeat expansion has been found to be the mutation underlying the condition. ${ }^{1213}$ The phenotype is variable and probably accounted for by the unstable expansion of the repeat but cases with psychiatric symptoms including schizophrenia in some families have been described (Naito et al, 1987 and Nakona et al, 1985, both in Japanese, quoted in reference 13). Mutations in the amyloid precursor protein (APP) gene are a rare cause of early onset familial Alzheimer's disease and in most cases the phenotype is characteristic. However, a mutation at codon 713 in exon 17 of the APP gene has been reported in a patient with schizophrenia with evidence of progressive cognitive decline. ${ }^{14}$ No other member of the proband's family had typical early onset Alzheimer's disease but the maternal grandmother had schizophrenia as did other members of her family. Of most relevance to the family discussed here, in the course of a study of a series of patients with schizophrenia, one person was found to have a huntingtin gene expansion mutation of 36 repeats, within the range for HD. ${ }^{15}$

Phenotypic heterogeneity has been noted in many neurodegenerative conditions. One favoured explanation for such heterogeneity has been that it is a reflection of heterogeneity at the molecular level, that different phenotypes are a result of different genotypes. However, cases such as that presented here suggest that there can be familial similarities in presentation, not caused by the known mutation associated with the primary disorder. In the family presented here, it appears that there is an additional familial factor influencing presentation of HD. Cases such as this serve to emphasise that there is a complex relationship between 
genotype and phenotype. Further studies of phenotypic similarities within families suffering from neurodegenerative conditions might provide important clues to the biological origin of psychotic phenomena.

We are grateful to Professor R Murray for comments on an earlier draft of this paper.

1 Huntington's Disease Collaborative Group. A novel gene containing a trinucleotide repeat that is expanded and unstable on Huntington's disease chromosomes. Cell 1993; unstable on

2 Watt DC, Seller A. A clinico-genetic study of psychiatric disorder in Huntington's chorea. Psychol Med 1993;suppl 23:1-46.

3 Dewhurst K, Oliver J, Trick K, McKnight A. Neuropsychiatric aspects of Huntington's disease. Confin Neurol 1969;31:255-8.

4 Bolt JMW. Huntington's chorea in the west of Scotland. $B$ 7 Psychiatry 1970;116:259-70.

5 Folstein S, Franz M, Jansen B, Chase G, Folstein M Conduct disorder and affective disorder among offspring of patients with Huntington's disease. Psychol Med 1983; 13:45-52.

6 Folstein S, Abbott M, Chase G, Jansen B, Folstein M. The association of affective disorder with Huntington's disease: in a case series and in families. Psychol Med 1983;13: in a case $537-42$.
7 Folstein S, Folstein M. Psychiatric features of Huntington's disease: recent approaches and findings. Psychiatr Dev 983;2:193-206.

8 Dewhurst K, Oliver JE, McKnight AL. Socio-psychiatric consequences of Huntington's disease. $\mathrm{Br} \mathcal{F}$ Psychiatry 1970;116:255-8.

9 Besson PS, Ebmeier KP, Simpson S. The clinical manifestation of mental disorder in Huntington's disease: a retrospective case record study of disease progression. Acta Psychiatr Scand 1991;83:53-60.

10 Jensen P, Sorensen SA, Fenger K, Bolwig TG. A study of psychiatric morbidity in patients with Huntington's disease, their relatives and controls. Admissions to psydisease, their relatives and controls. Admissions to psy-
chiatric hospitals in Denmark from 1969 to 1991. Br f Psychiatry 1993;163:790-7.

11 Baxter LR, Mazziotta JC, Pahl JJ, et al. Psychiatric, genetic and positron emission tomographic evaluations of persons at risk for Huntington's disease. Arch Gen Psychiatry 1992; 49:148-54.

12 Koide R, Ikeuchi $\mathrm{T}$, Onodera $\mathrm{O}$, et al. Unstable expansion of CAG repeat in hereditary dentatorubral-pallidoluysian atrophy (DRPLA). Nature Genet 1994;6:9-13.

13 Nagafuchi S, Yanagisawa $\mathrm{H}$, Sato K. Dentatorubral and pallidoluysian atrophy; expansion of an unstable CAG trinucleotide on chromosome 12p. Nature Genet 1994;6: 14-18.

14 Jones CT, Morris S, Yates CM, et al. Mutation in codon 713 of the $\beta$ amyloid precursor protein gene presenting with schizophrenia. Nature Genet 1992;1:306-9.

15 St Clair D. Expanded CAG trinucleotide repeat of Huntington's disease gene in a patient with schizophrenia and normal striatal histology. $\mathcal{f}$ Med Genet 1994;31:658-9. 